\title{
Biostimulation in primiparous postpartum acyclic early weaned beef cows: introducing the bulls at weaning advances cyclic rebreeding
}

\author{
Rodolfo Ungerfeld ${ }^{\mathfrak{t}}$ \\ Departamento de Fisiología, Facultad de Veterinaria, Universidad de la República, Montevideo, Uruguay.
}

\begin{abstract}
Weaning and biostimulation promote an early cyclic postpartum rebreeding. Although the signals and mechanisms by which weaning and biostimulation differ, both end stimulating LH secretion. The aim of the experiment was to determine if weaning and biostimulation have additive effects advancing the postpartum rebreeding in primiparous postpartum anoestrous cows. The experiment was performed during late spring - early summer with 51 primiparous Hereford cows. Six weeks after parturition calves were weaned, and cows were managed in two experimental groups: WB $(\mathrm{n}=22)$ and WDB $(\mathrm{n}=29)$. Bulls were joined with WB cows at weaning, but joining was delayed one week in WDB cows. The presence of corpora lutea in the ovaries was recorded weekly with ultrasound, and 28 and 50 days after the end of the exposure period, pregnancy was determined by ultrasound. The percentage of cyclic cows was greater in WB than in WDB on Weeks 8 (36.4 vs $0 \%), 968.2$ vs $13.8 \%), 10$ (86.4 vs $27.6 \%$ ) and 11 $(100.0$ vs $37.9 \%)(\mathrm{P}<0.001$ in all $)$. Cows that were weaned and biostimulated simultaneously rebred earlier than WDB cows (Week $9.1 \pm 0.2$ vs Week $11.0 \pm 0.2 ; \mathrm{P}$ $<0.0001)$. At the end of the experiment 46/51 (90.2\%) of the animals were cycling. Pregnancy rate tended to be greater in WB than WDB cows 28 days after the end of the breeding period $18 / 22$ vs $17 / 29, \mathrm{P}=0.077$ ), but there was no difference at the end of the study $(20 / 22$ vs $24 / 29$, ns). In conclusion, the application of weaning and biostimulation simultaneously advances postpartum rebreeding more than weaning alone in beef cows.
\end{abstract}

Keywords: anestrus, cattle, ovulation, socio-sexual stimulus, suckling.

\section{Introduction}

Lactation has negative effects on cyclic rebreeding in postpartum cows as it increases the energetic requirements. However, suckling also has a direct effect inhibiting postpartum rebreeding: early weaned cows come into estrus and ovulate earlier than nursed cows (Acosta et al., 1983; Quintans et al., 2009). This inhibition is mediated by the negative effect that suckling has in the secretion of LH pulses (Stagg et al., 1998). In this sense, weaning triggers a rapid increase in LH secretion (Stagg et al., 1998). Thus, weaning has also positive effects in the response to estrous synchronization treatments (Geary et al., 2001). Therefore, different weaning strategies have been developed to increase LH secretion, and thus, advance postpartum rebreeding.
Another strategy to stimulate an advancement of postpartum rebreeding is biostimulation (see review: Fiol and Ungerfeld, 2011). In many studies it has been reported that exposure to males stimulates cyclic activity in postpartum cows (Zalesky et al., 1984; Alberio et al., 1987; Landaeta-Hernández et al., 2004; Berardinelli and Joshi, 2005; Landaeta-Hernández et al., 2006). The introduction of bulls, or even androgenized steers stimulates an increase in LH pulse secretion in postpartum cows (Fernandez et al., 1996; Tauck et al., 2010) and anestrous heifers (Fiol and Ungerfeld, 2016).

Therefore, both, weaning and biostimulation promote an early cyclic postpartum rebreeding. Although the signals and mechanisms by which weaning and biostimulation differ (see reviews, for postpartum: Williams et al., 1996; for biostimulation: Fiol and Ungerfeld, 2011), both end stimulating LH secretion. In this sense, Silva Filho et al. (2016) reported that the combination of biostimulation and temporary weaning decreased the number of services required per conception and increased the pregnancy rate achieved in beef cows compared to biostimulation itself after an estrous synchronization treatment. However, it is not known if, as both practices end triggering the same endocrine response, the simultaneous application of weaning and biostimulation have synergistic effects. Therefore, the aim of the experiment was to determine if weaning and biostimulation have additive effects advancing the postpartum rebreeding in primiparous postpartum anoestrous cows.

\section{Methods}

\section{Animals and location}

The experiment was performed in a commercial farm located in Soriano, Uruguay, $\left(33^{\circ} \mathrm{S}\right)$ between November and January (late spring - early summer) with 51 primiparous Hereford cows. Six weeks after parturition calves were weaned, and cows were managed in two experimental groups: WB $(n=22)$ and WDB $(n=29)$ (body condition $=2.79 \pm 0.09$; scale 1 to 8). Bulls were joined with WB cows at weaning, but joining was delayed one week in WDB cows. Body condition score (scale of one to eight: one = extremely emaciated, eight $=$ excessively fat) was evaluated at the beginning and at the end of the experiment by the same observer.

Four 4-6-yr-old Angus bulls were selected according to a breeding soundness evaluation performed one month before beginning the experiment. Evaluation included a general physical examination and a particular reproductive exam of testicles and epydidimus. 


\section{Ultrasonographic evaluation}

The presence of corpora lutea in the ovaries was recorded weekly with ultrasound, using a Chison 500 Vet machine with a $7.5 \mathrm{MHz}$ linear probe (Chison Medical Imaging, Wuxi, China). Ultrasound scanning began one week before weaning and continued 6 weeks more after weaning. Resumption of cyclic activity was considered as the first date that a corpus luteum was observed if it was observed in two successive scans in the same ovary. Twenty-eight and fifty days after the end of the exposure period, pregnancy was determined by ultrasound.

\section{Statistical analyses}

The accumulated frequencies of cows with corpus luteum per week, and the final pregnancy rates were compared using chi square tests. Intervals to resumption of cyclic activity were compared with ANOVA and are presented as mean \pm SEM. Birth was considered as Week 0 .

\section{Results}

No ovulation was detected until Week 8 (second week after weaning). However, at the end of the experiment $46 / 51(90.2 \%)$ of the animals were cycling. The percentage of cyclic cows was greater $(\mathrm{P}<0.001)$ in WB than in WDB on Weeks 8, 9, 10 and 11 (Fig. 1). Cows that were weaned and biostimulated simultaneously (WB cows) rebreed earlier than WDB cows (Week $9.1 \pm 0.2$ vs Week $11.0 \pm 0.2 ; \mathrm{P}<0.0001$ ).

Pregnancy rate tended to be greater in WB tan WDB cows 28 days after the end of the breeding period $18 / 22$ vs $17 / 29, \mathrm{P}=0.077)$, but there was no difference at the end of the study (20/22 vs $24 / 29$, ns).

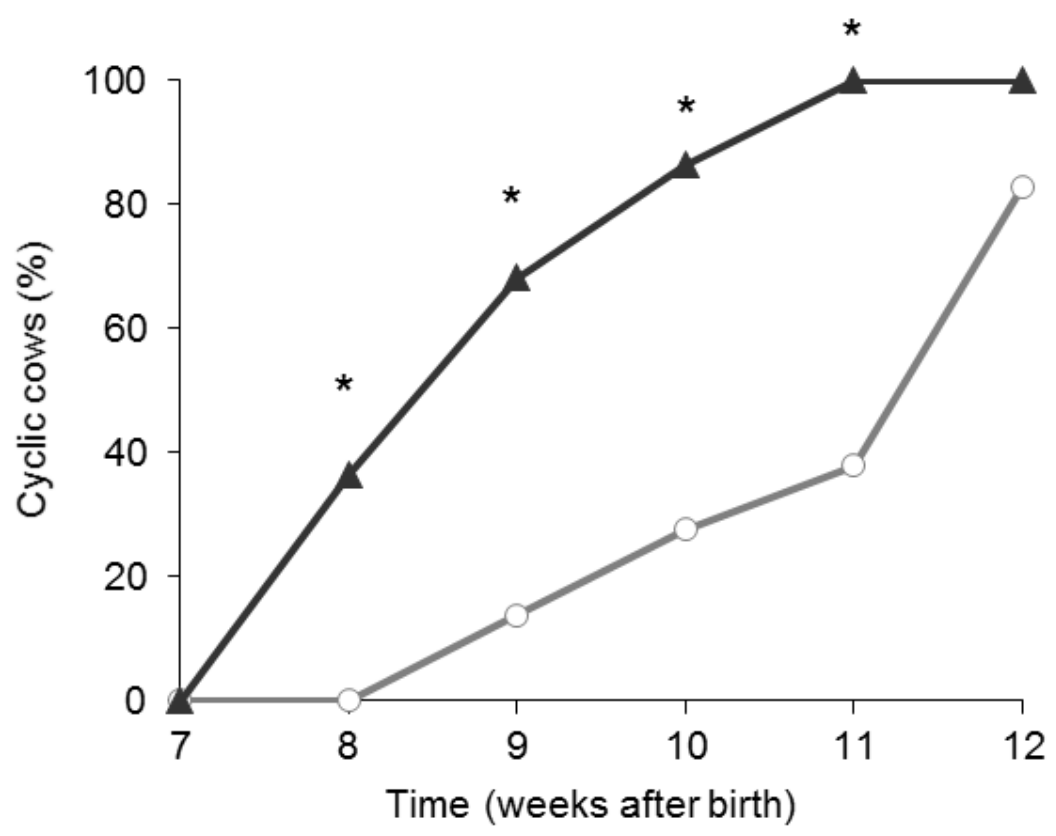

Figure 1. Percentage of cyclic cows after weaning (performed on Week 6), and joined with bulls on Week $6(-\boldsymbol{\Delta}-, n=22)$ or Week $7\left(-\bigcirc_{-}, n=29\right)$. All were primiparous Hereford cows.

\section{Discussion}

Biostimulation applied simultaneously to weaning increased the proportion of cows that ovulated, as ovulation was delayed in the cows biostimulated one week later. Therefore, both practices can be applied simultaneously to advance rebreeding even more than with each of the practices alone. Although it has been clearly demonstrated that weaning is the strongest stimulation for rebreeding (Williams et al., 1996), the simultaneous introduction of bulls potentiates the response to early weaning. From a practical view, these results open interesting possibilities for natural breeding in "clean" systems (Martin and Kadokawa, 2006).

Although weaning and biostimulation probably triggered an increase in LH pulsatility, the simultaneous application of both practices advanced more the first ovulation that each one alone. This means that each is not triggering the maximum response or that the response is greater because both act through different mechanisms. Introduction of bulls induces an increase of LH (Fiol and Ungerfeld, 2016), as happens in anoestrous sheep and goats (Delgadillo et al., 2009). As suckling increases the synthesis of endogenous opioid (that inhibit GnRH secretion) and the central negative sensibility to oestrogens, weaning removes this inhibition. Therefore, as both stimulus advanced the response, it is probably that each one alone could not trigger the maximum increase in $\mathrm{LH}$ secretion.

In this study, cows were weaned and biostimulated shortly after birth, but most commonly, these managements are applied at later postpartum 
stages. In this sense, the possible advantages of the $\mathrm{GnRH}$ and $\mathrm{LH}$ secretions are probably more sensitive for responding to external stimuli at later postpartum periods.

In conclusion, the application of weaning and biostimulation simultaneously advanced postpartum rebreeding more than weaning alone in primiparous Hereford cows.

\section{Acknowledgements}

The author acknowledge Francesca CarregaBertolini, Silvana González and Alejandra Ramos for their participation in the field work; Alejandro Urchipia and Juan José Rodríguez for the organization of the study at the field. Financial support: Tursel SA, Fundaciba.

\section{Conflict of interest}

The author declare no conflicts of interest exist that are of influence on this work.

\section{References}

Acosta B, Tarnavsky GK, Platt TE, Hamernik DL, Brown JL, Schoenemann HM, Reeves JJ. 1983. Nursing enhances the negative effect of estrogen on LH release in the cow. J Anim Sci, 57:1530-1536.

Alberio RH, Schiersmann G, Carou N, Mestre J 1987. Effect of teaser bull on ovarian and behavioural activity of suckling beef cows. Anim Reprod Sci, 14:263-272.

Berardinelli JG, Joshi PS. 2005. Initiation of postpartum luteal function in primiparous restrictedsuckled beef cows exposed to a bull or excretory products of bulls or cows. J Anim Sci, 83:2495-2500.

Delgadillo JA, Gelez H, Ungerfeld R, Hawken PAR, Martin GB. 2009. Revisiting the dogmas surrounding the mechanisms involved in the male effect in sheep and goats. Behav Brain Res, 200:304-314.

Fernandez DL, Berardinelli JG, Short RE, Adair R. 1996. Acute and chronic changes in luteinizing hormone secretion and postpartum interval to estrus in first-calf suckled beef cows exposed continuously or intermittently to mature bulls. J Anim Sci, 74:1098-1103. Fiol C, Ungerfeld R. 2016. Positive effects of biostimulation on LH concentration and follicular development in anestrous beef heifers. J Anim Sci, 94:1-7. Fiol C, Ungerfeld R. 2011. Biostimulation in cattle: including these managements may be even greater, as stimulation pathways and mechanisms of response. Trop Subtr Agroec, 15 Suppl 1:S29-S45.

Geary TW, Whittier JC, Hallford DM, MacNeil MD. 2001. Calf removal improves conception rates to the Ovsynch and CO-Synch protocols. J Anim Sci, 79:1-4.

Landaeta-Hernández AJ, Giangreco M, Meléndez P, Bartolomé J, Bennet $\mathbf{F}$, Rae DO, Hernández J, Archbald LF. 2004. Effect of biostimulation on uterine involution, early ovarian activity and first postpartum estrous cycle in beef cows. Theriogenology, 61:15211532.

Landaeta-Hernández AJ, Meléndez P, Bartolomé J, Rae DO, Archbald LF. 2006. Effect of biostimulation on the expression of estrus in postpartum Angus cows. Theriogenology, 66:710-716.

Martin GB, Kadokawa H. 2006. "Clean, green and ethical" animal production. Case study: reproductive efficiency in small ruminants. $J$ Reprod Dev, 52:145152.

Quintans G, Vázquez AI, Weigel KA. 2009. Effect of suckling restriction with nose plates and premature weaning on postpartum anestrous interval in primiparous cows under range conditions. Anim Reprod Sci, 116:10-18.

Silva Filho ML, Bezerra LR, Ferreira-Silva JC, Souto FM, Oliveira NR, Lima PF, Bartholomew CC, Oliveira MAL. 2015. Influence of biostimulation and temporary weaning on follicular dynamics and pregnancy rates in Nelore cows (Bos taurus indicus). Trop Anim Health Prod, 47:1285-1291.

Stagg K, Spicer LJ, Sreenan JM, Roche JF, Diskin MG. 1998. Effect of calf isolation on follicular wave dynamics, gonadotropin and metabolic hormone changes, and interval to first ovulation in beef cows fed either of two energy levels postpartum. Biol Reprod, 59:777-783

Tauck SA, Olsen JR, Wilkinson JRC, Berardinelli JG. 2010. Duration of daily bull exposure on resumption of ovulatory activity in postpartum, primiparous, suckled, beef cows. Anim Reprod Sci, 118:13-18.

Williams GL, Gazal OS, Guzman Vega GA, Stanko RL. 1996. Mechanisms regulating suckling-mediated anovulation in the cow. Anim Reprod Sci, 42:289-297.

Zalesky DD, Day ML, Garcia Winder M, Imakawa K, Kittok RJ, D'Occhio MJ, Kinder JE. 1984. Influence of exposure to bulls on resumption of estrous cycles following parturition in beef cows. J Anim Sci, 59:1135-1139. 